\title{
QTL Mapping for Resistance to Early Blight in a Tetraploid Potato Population
}

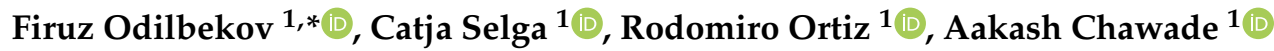 \\ and Erland Liljeroth ${ }^{2}$ (D)
}

1 Department of Plant Breeding, Swedish University of Agricultural Sciences, P.O. Box 101, SE-230 53 Alnarp, Sweden; catja.selga@slu.se (C.S.); rodomiro.ortiz@slu.se (R.O.); aakash.chawade@slu.se (A.C.)

2 Department of Plant Protection Biology, Swedish University of Agricultural Sciences, P.O. Box 102, SE-230 53 Alnarp, Sweden; Erland.Liljeroth@slu.se

* Correspondence: firuz.odilbekov@slu.se; Tel.: +46-738750151

Received: 24 March 2020; Accepted: 14 May 2020; Published: 19 May 2020

\begin{abstract}
Early blight of potato, caused by Alternaria solani, is an economically important foliar disease in most potato-growing regions. Growing cultivars with higher levels of resistance to early blight can reduce tuber yield losses and the need for fungicide applications. In this research, a bi-parental tetraploid potato population, segregating for resistance to early blight in leaves and tubers, was characterized to identify novel quantitative trait loci (QTL) associated with foliar and tuber early blight resistance. Assessment of the disease resistance in the foliage was performed by field evaluation and in tuber under controlled conditions. Results from this study revealed significant differences $(P<0.001)$ in resistance to $A$. solani among potato clones both in the leaves and in tubers. There was no statistically significant correlation $(\mathrm{r}=0.06, P=0.35)$ between the resistance scores from leaves and tubers. Several clones exhibited; however, high levels of resistance both in leaves and tubers and are; thus, promising candidates for breeding for early blight resistance. Linkage mapping revealed several QTL for early blight affecting both foliage and tubers. QTL associated with disease resistance in the tuber were found on chromosomes 1, 2, 3, 4, 8, 11 and 12. QTL associated with disease resistance in foliage were also examined for independence from defoliation, and independent QTL were; thus, found on chromosomes 5 and 11.
\end{abstract}

Keywords: Alternaria solani; crossed population; QTL tuber resistance; early blight

\section{Introduction}

Potato (Solanum tuberosum L.) is considered the third most important food crop in the world and is cultivated in approximately 125 countries [1]. The production of potato can be affected by several pests and pathogens in which early blight (EB) takes an important place in tuber yield losses [2]. EB caused by the fungus Alternaria solani is an important disease of potato, especially in regions with high temperatures and periods with alternating dry and humid conditions promoting infections $[3,4]$. The pathogen can also cause dry rot on tubers, which affect both the quantity and quality of tubers during the storage. However, in Europe, it is not considered as an economically important disease, but losses during storage of up to $30 \%$ have been reported from other parts of the world [5,6]. During recent years, the problems with EB on potato seem to have increased in Europe $[4,7,8]$. Moreover, EB has been more frequently observed in potato fields in northern countries of Europe such as Sweden [9], where it earlier was of minor economic importance. Fungicide application is the main practice adopted worldwide for controlling foliar EB, and growers commonly apply fungicides several times from the beginning of the growing season until defoliation $[10,11]$. However, repeated use of fungicides creates a high risk for development of resistance in the pathogen population [12-14]. Furthermore, social and 
environmental concerns demand a significant reduction of fungicides and abundant applications of chemicals may also decrease the concept of potato being a healthy food [15].

Host plant resistance remains as the most appropriate method for controlling EB, as also noted for other diseases affecting the potato crop. Gaining insights on the genetics and related mechanisms of resistance provides guidance for host plant resistance breeding to EB. Thus far there are no specific $R$ genes identified for controlling $\mathrm{EB}$, suggesting that resistance trait to EB displays a quantitative inheritance pattern [16,17]. EB resistance in potato germplasm has been investigated thoroughly [17-21]. Thus far resistance to EB is characterized by a typical rate-decreasing resistance reaction [20]. It has been observed that potato resistance to EB is related to the maturity of cultivars, where late-maturing cultivars are more resistant than early maturing cultivars [10,20,22]. Boiteux et al. [22] assessed different potato clones for their susceptibility to EB and found a good correlation between resistance and late maturity, but some clones showed both resistance and early maturity. A similar result was obtained by Zhang [23] in diploid potato, where early- or mid-season maturing clones of potato revealed a high level of resistance. It was also found that EB resistance is highly heritable in diploid hybrid populations [24,25] as well as in crosses between tetraploid and diploid clones [16,26]. Zhang [23] studied the genetics of resistance to EB in diploid potato and observed that these two traits (resistance and maturity) could be separately determined although they were closely linked. Zhang [23] also identified five quantitative trait loci (QTL) on chromosomes 4, 5, 9, 11 and 12 linked to EB resistance. Among them, two QTL on chromosomes 4 and 5 were mapped for foliage maturity and the other three QTL on chromosomes 9, 11 and 12 were linked to EB resistance.

Tetraploid potato $(2 n=4 x=48)$ is highly heterozygous and, with its complex polyploid genetics, presents a challenge for linkage mapping as well as for analysis of quantitative trait loci (QTL) [27]. However, with the recent progress in genotyping platforms $[28,29]$ as well as the sequenced potato genome [30], high-density genotyping of tetraploid potato has become possible. Currently, this approach has been used to identify novel QTL and markers associated with different agronomic traits such as late blight resistance [31-33], virus resistance [34], tuber quality [35] and other agronomic traits [36]. Santa et al. [33] in their study identified six QTL linked to Phytophthora infestans and 15 QTL were mapped for Tecia solanivora in tetraploid potato. Da Silva et al. [34] revealed several major-effect QTL related to Potato virus $Y$ on chromosomes 4 and 5.

Thus far, the genetic background of EB resistance in tetraploid potato has remained unexplored. Hence, in the present study, we used a $F_{1}$ tetraploid potato segregating population derived from a cross between the cultivars "Matilda" (susceptible) $\times$ "Magnum Bonum" (resistance) to identify novel QTL associated with foliar and tuber EB resistance.

\section{Materials and Methods}

\subsection{Plant Material and Crossing}

In a previous study, we applied various methods and conditions for screening potato cultivars and clones for resistance against EB [19]. Based on this study, two potato cultivars, "Magnum Bonum" (resistant to EB) and "Matilda" (susceptible to EB) were chosen as parents. The crossing ("Matilda" $\times$ "Magnum Bonum") was performed in 2012 under greenhouse conditions according to Tiemens-Hulscher et al. [37]. Potato berries were collected, and the seeds were extracted and stored at room temperature for further study. In 2013, around 100 seeds were randomly chosen, surface-sterilized in 1\% sodium hypochlorite for $3 \mathrm{~min}$ and then washed twice in sterile distilled water. After sterilization, the potato seeds were grown in tissue culture $\left(16 \mathrm{~g} / \mathrm{L}^{-1}\right.$ of phytoagar, $40 \mathrm{~g} / \mathrm{L}^{-1}$ of sucrose and $4.4 \mathrm{~g} / \mathrm{L}^{-1}$ of murashige and skoog medium ) in a growth chamber with $16 \mathrm{~h}$ of light $(140 \mu \mathrm{E})$, at $22^{\circ} \mathrm{C}$ for 3 weeks, in order to get enough number of clones. Plants were then transferred to $3.5 \mathrm{~L}$ plastic pots filled with commercial pot soil (Yrkesplantjord, Weibulls, Sweden) to a greenhouse chamber with adjusted temperature to $22{ }^{\circ} \mathrm{C}$ and natural light supplemented with $15 \mathrm{~h}$ artificial light. Tubers of 80 progenies were harvested after 12 weeks and kept in storage at $4{ }^{\circ} \mathrm{C}$ with a relative humidity varying between $70 \%$ and $75 \%$. 


\subsection{Field Experiments}

Three field experiments were carried out in 2014, 2015 and 2016 at the Swedish Rural Economy and Agricultural Societies experimental farm in Kristianstad, Sweden. The field sites were particularly selected for their natural sources of $A$. solani and as well as based on our previous experiments $[14,19]$. Tubers from 80 offspring clones were planted in a randomized complete block design, with four blocks, in June in all three years, where each block contained 4-6 plants. To protect plants against late blight, the trial was treated with fungicides, without effect on EB, every week (Revus $0.6 \mathrm{~L} / \mathrm{ha}$ and Ranman Top $0.5 \mathrm{~L} /$ ha were alternated). The first typical EB symptoms appeared relatively late in the season (i.e., in the middle of August for both 2014 and 2016). However, no EB symptoms have appeared in the field experiment in 2015. In 2014, plants were scored for A. solani symptoms two times-17 and 23 September. In 2016, the plants were scored four times-26 August plus 12, 19 and 26 September. At each assessment, plants were visually rated for $A$. solani infection. The percentage of the green canopy with typical EB symptoms was scored according to the European Plant Protection Organization scale [38], and at the same time, the degree of defoliation was determined with the same scale. The relative area under the disease progress curve (rAUDPC) was calculated as a measurement of disease severity over the season. Similarly, the relative area under the defoliation curve (rAUC) was calculated. The AUDPC was calculated based on the following formula:

$$
\operatorname{AUDPC}=\sum_{i=1}^{n-1}\left[\left(Y_{i}+Y_{i+1}\right) / 2\right]\left[X_{i+1}-X_{i}\right],
$$

where $Y_{i}$ is disease severity in percent at the $i$ th observation, $X i$ is time (days) at the $i$ th observation and $\mathrm{n}$ is the total number of observations. The relative AUDPC (rAUDPC) was calculated by dividing AUDPC by the total area during the assessment period, assuming $100 \%$ disease from the start. rAUC was calculated in the same way using data from assessment of defoliation rates at the same time points. During the growing season (every second week), leaf samples were collected to verify the presence of A. solani in the field. Morphological identification of A. solani isolates done based on Simmons [39], and the identifications were confirmed by PCR using species-specific primers [40].

\subsection{Inoculum Preparation}

Fungal cultures were prepared as described by Odilbekov et al. [19]. In short, a single spore culture of A. solani (isolate AS8) obtained from naturally infected potato plant leaves in Sweden was grown on potato dextrose agar at $22{ }^{\circ} \mathrm{C}$ for 7 days followed by incubation under UV light (100-280 nm) for $24 \mathrm{~h}$. After the incubation, culture was kept for 7 days in dark condition and after that the conidia was surface-sterilized by washing the plates with $\mathrm{ddH}_{2} \mathrm{O}$. The spore concentration was adjusted to $10^{4}$ conidia $\mathrm{mL}^{-1}$.

\subsection{Tuber Resistance Test}

Tubers of all progenies were harvested from the field experiment in 2014 and kept in storage at $4{ }^{\circ} \mathrm{C}$ with a relative humidity varying between $70 \%$ and $75 \%$ for four months. After storage, tubers were cut in two pieces and accommodated in $60 \times 30 \mathrm{~cm}$ plastic boxes with lids having filter paper and a plastic net placed in the bottom. Distilled water was added to the filter paper to provide high relative humidity. Tubers were arranged in three randomized complete blocks and the experiment was repeated once. The interval between the first and second experiment was one month. The tubers were drop inoculated with $50 \mu \mathrm{L}$ of conidial suspension in the center of the cut side and incubated in the dark at $18{ }^{\circ} \mathrm{C}$. After 16 days, the lesion diameter and lesion depth were measured. The volume of infected tuber tissue was calculated based on lesion diameter and depth using the following formula:

$$
V=\frac{2}{3} \pi b^{2} a,
$$


where $b$ is the radius of the lesion on the tuber surface and $a$ is the depth of the lesion.

\subsection{Data Analysis}

Minitab software package (Version 16) was used for statistical calculations. Differences in percent of infection in leaves and volume infection on tubers were investigated with the analysis of variance (ANOVA) generalized linear model (GLM). Pearson's correlation coefficients were used to investigate the associations between different variables. Estimation of the clonal variance $\left(\sigma^{2} \mathrm{C}\right)$, year $\times$ clone variance $\left(\sigma^{2} \mathrm{YC}\right)$ and the error variance $\left(\sigma^{2} \mathrm{e}\right)$ were calculated using the linear mixed model [41] using the SOMMER package in $\mathrm{R}$. The broad-sense heritability $\left(\mathrm{H}^{2}\right)$ was calculated from these estimates of variances as:

$$
\mathrm{H}^{2}=\sigma^{2} \mathrm{C} /\left(\sigma^{2} \mathrm{C}+\sigma^{2} \mathrm{YC} / \mathrm{y}+\sigma^{2} \mathrm{e} / \mathrm{b}\right)
$$

where $y$ is the number of years and $b$ is the number of blocks.

\subsection{Linkage Mapping and QTL Analysis}

For the construction of the linkage map and the QTL analysis, TetraploidMap for Windows was used [42]. TetraploidMap has been used to construct linkage maps in tetraploid potato in previous research and to map traits such as tuber chip colour [43], yield [44] and heat stress [45]. Genomic data for parents and offspring were collected using a 10K single nucleotide polymorphism (SNP) array. This SNP genotyping was performed by the breeding company HZPC, Joure, The Netherlands. Significant simplex $(P<0.001)$ and duplex $(P>0.01)$ markers were selected based on a $\chi^{2}$-test. Markers were further excluded if there were missing data for parents and having an overall missing data above $10 \%$. Lastly, SNPs with a Spearman's correlation of above 0.99 were also excluded. Parental genotypes were determined at each locus, and only SNPs that could be derived to a single parent were included in the analysis. Parental genotypes for each SNP were determined by looking for polymorphic SNPs between the two parents, having one homozygote and one heterozygote parental genotype for each SNP. Linkage analysis and QTL mapping were subsequently carried out separately for the two parents. Only two marker types were selected for the construction of the linkage map: (1) Simplex-dominant markers with a $P$-value below 0.001 , and (2) duplex-dominant markers with a $P$-value below 0.01 . The difference in the stringency of the $\chi^{2}$ tests is because a distorted duplex marker will have a bigger impact on the linkage map, than a simplex marker. All designated markers were partitioned into linkage groups by using group cluster analysis [46]. The linkage map for "Magnum Bonum" included 415 SNPs and the linkage map for "Matilda" included 403 SNPs. Marker ordering was done by looking at recombination frequencies and the logarithm of the odds ratio (LOD scores) between each pair of SNPs. The likely phase between each pair of SNPs was calculated using the recombination frequency and LOD score between all pairs of markers. Weighted least squares were used for ordering, using three options built into TetraploidMap-two-point linkage analysis, initial run "custom" marker ordering and "ripple". The interval mapping approach was used for QTL detection, as previously described by Hackett et al. [47]. Three phenotypic traits were included for the QTL analysis; foliar resistance to EB (mean rAUDPC over two years, 2014 and 2016), defoliation (mean rAUC over three years 2014, 2015 and 2016) and tuber resistance to EB (mean over two experiments). The genetic maps were also linked to the phenotypic data for each of the years that foliage resistance to EB and defoliation were collected (2014, 2015 and 2016) separately, to detect any possible differentiations between the two years. QTL were identified either as simplex- or duplex-dominant or additive, default settings for signal threshold was used (100 permutations). A reduced model was reported when it did not significantly differ from the full model. A QTL was declared to be significant $(P<0.1)$ if the peak LOD score was above 2 , and passed the $90 \%$ distribution point for the permutation test. The QTL was declared to be independent from other phenotypic traits if the respective QTL regions did not overlap. The main effect was determined for significant QTL that were identified with a duplex or simplex model. QTL effect was estimated as the mean phenotypic value for all offspring with either of the two 
possible parental genotypes (homozygote or heterozygote) at the locus in closest proximity to the QTL. The effect was rendered positive if the offspring phenotype was closer to the parental phenotype from which the marker had been inherited.

\section{Results}

\subsection{Phenotyping}

In the present study, we evaluated resistance to EB in a bi-parental population of tetraploid potato. The results from the field evaluations revealed significant differences $(P<0.001$, Table 1$)$ in host plant resistance to EB as well as in defoliation among the progeny clones. The average foliar rAUDPC ranged from 0.02 to 0.14 , and the average foliar rAUC ranged between 0.06 and 0.4 among the clones, respectively (Figure 1A,B and Supplementary Figure S1). A higher significant correlation was observed between the average of foliar rAUDPC and rAUC (Figure 2A, $r=0.85, P=0.001$ ). We have also found a significant correlation $(\mathrm{r}=0.32, P=0.001)$ between $\mathrm{rAUDPC}$ from 2014 and rAUDPC from 2016 and as well as between rAUC from 2015 and rAUC from $2016(\mathrm{r}=0.61, P=0.001)$, respectively. However, lower correlation was found between the rAUC from 2014 and rAUC $2015(\mathrm{r}=0.058)$ or rAUC $2016(\mathrm{r}=0.20$, $P=0.001$ ). Clones K16, K24, K21 and K23 exhibited higher levels of resistance, whereas lower levels were found in clones K9, K64, K58 and K34 (Supplementary Figure S2). The data from the tuber test revealed that there were significant differences $(P<0.001)$ in lesion size and lesion depth development among clones after inoculation of cut tubers with A. solani. A significant correlation (Figure $2 \mathrm{~B}, \mathrm{r}=0.65$, $P<0.001)$ was also found between these two measurements. In addition, calculations of the volume of the infected area (VIA) revealed significant differences $(P<0.001)$ among the clones in the bi-parental population. The distribution of the means of the VIA of tubers ranged from 0.5 to 6 (Figure 1C). Clones K54, K23, K2 and K66 showed the highest level of resistance and the most susceptible clones in tuber test were K57, K67, K18 and K39 (Supplementary Figure S2). The results from the present work revealed that the degree of resistance in foliage did not correlate with resistance on tubers (Figure 2C, $\mathrm{r}=0.06, P=0.35$ ). The cultivar "Matilda" as a susceptible parent of this crossing population had better resistance to EB in the tuber than the EB resistant parent "Magnum Bonum". Several clones exhibited; however, high levels of resistance both in foliage and tubers (Supplementary Figure S2). The broad-sense heritability $\left(\mathrm{H}^{2}\right)$ of foliar and tuber EB resistance are given in Table 1. A higher level of heritability was estimated in the defoliation $(64 \%)$ in comparison to foliar resistance to EB (48\%).
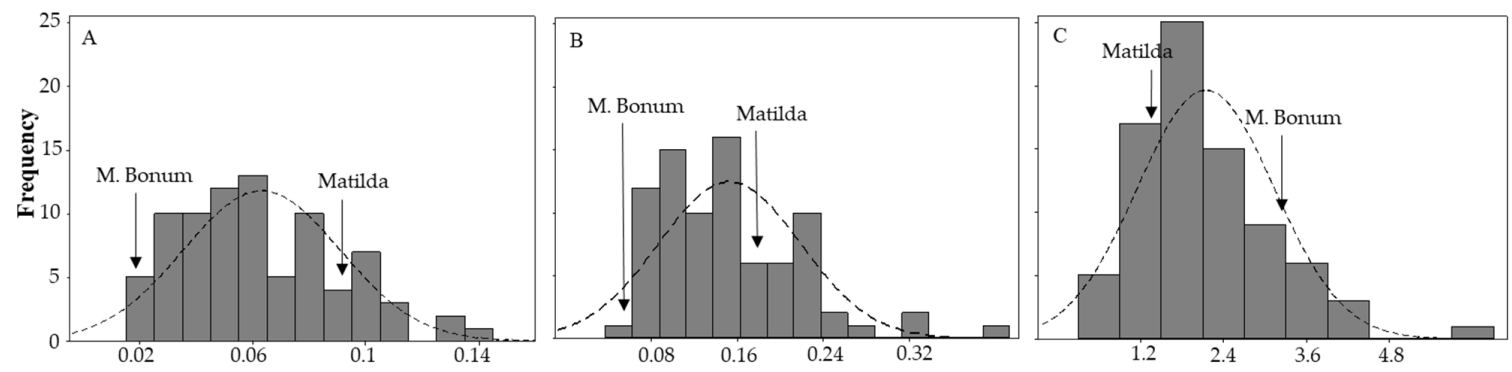

Figure 1. Phenotype distributions of (A) relative area under the disease progress curve (rAUDPC); (B) relative area under the defoliation curve (rAUC) and (C) volume of the infected area on tubers $\left(\mathrm{cm}^{3}\right)$ for early blight disease among the offspring. 
Table 1. Analysis of variance for foliar resistance and defoliation.

\begin{tabular}{ccccccc}
\hline \multicolumn{7}{c}{ Foliar Resistance } \\
\hline Source of Variation & DF & SS & MS & F & P-Value & $\mathbf{H}^{\mathbf{2}}$ \\
\hline Clone & 81 & 0.4979 & 0.0061 & 3.08 & $2.83 \times 10^{-14}$ & 0.48 \\
Error & 571 & 1.167 & 0.0020 & & & \\
Total & 653 & 1.665 & & & & \\
\hline \multicolumn{7}{c}{ Defoliation } \\
Clone & 81 & 5.931 & 0.0732 & 5.65 & $2 \times 10^{-16}$ & 0.64 \\
Error & 899 & 11.657 & 0.0130 & & & \\
Total & 980 & 17.588 & & & & \\
\hline
\end{tabular}

DF: Degrees of freedom; SS: Sum of squares; MS: Mean squares; F: F-test value; $\mathrm{H}^{2}$ : Broad-sense heritability estimate.
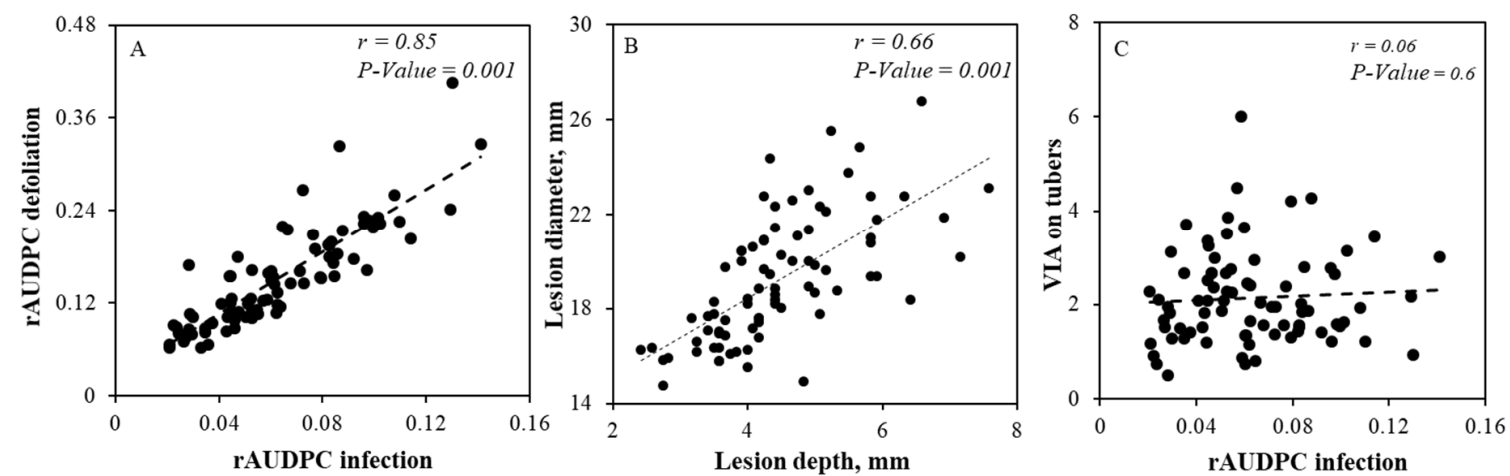

Figure 2. Correlation between (A) relative area under the disease progress curve (rAUDPC) and relative area under the defoliation curve (rAUC), (B) lesion diameter and lesion depth on tuber and (C) volume of the infected area (VIA) on tuber and relative area under the disease progress curve (rAUDPC).

\subsection{Linkage Map Construction}

In total, 7386 SNPs could be scored in the population, out of these, 415 could be used for developing the linkage map for "Magnum Bonum" and 403 for "Matilda". The linkage map for "Magnum Bonum" contained 36 linkage groups with a total genetic distance of $1250 \mathrm{cM}$. The linkage map for "Matilda" had a slightly smaller genetic distance compared to that of "Magnum Bonum" (i.e., $1122 \mathrm{cM}$ ). The linkage map for "Matilda" contained 31 linkage groups. The 12 chromosomes were included in both of the parental linkage maps, with an average of 34.6 SNPs per chromosome $\left(s^{2}=126.8\right)$ and 33.6 SNPs per chromosome $\left(\mathrm{s}^{2}=181.7\right)$ for "Magnum Bonum" and "Matilda", respectively. The SNPs in chromosomes 3 and 8 for "Matilda" were mapped using one single linkage group. These linkage groups contained 26 and 17 SNPs, respectively. The other chromosomes for the two linkage maps were plotted using between two and four linkage groups per chromosome.

In total, 33 significant QTL were found for the traits tuber resistance to EB, foliar resistance to EB and defoliation, with an even distribution of 11 QTL per trait (Table 2, Supplementary Figures S3 and S4). Figure 3 shows the probable dependency of the QTL between the different phenotypic traits. The 11 QTL for resistance to EB in the tuber was found distributed on chromosomes 1, 2, 3, 4, 5, 8, 11 and 12. EB in tubers had the highest number of QTL predicted to be independent from the other two phenotypic traits. Four QTL were found in both tuber and foliar resistance to EB, and three were found in tuber resistance to EB and defoliation. Three QTL were predicted to have a major effect, contributing to around $50 \%$ of the phenotypic variation explained (PVE), these were found on chromosomes 2, 8 and 11. The predicted regions of the QTL on chromosomes 2 and 8 were only found for tuber resistance to EB, while the major QTL on chromosome 11 cannot be declared independent from the QTL for foliar resistance on the same chromosome. However, this remains uncertain as the signals were found in two separate parental linkage maps. The number of QTL for EB resistance in foliage with a possible overlap 
with (i.e., cannot be declared independent from) QTL for defoliation was high $(N=9)$, compared to the possible overlap with EB resistance in tubers $(N=4)$. Only one QTL did not overlap with other QTL on the same linkage map, or corresponding chromosomes in the other parental linkage map. Most QTL for foliar resistance to EB were found on chromosome $5(N=4)$; however, QTL were also found on chromosomes 1, 6, 7, 11 and 12. In total, two QTL for foliar resistance to EB were independent from QTL for defoliation. The two QTL that did not overlap with the area of the defoliation QTL were found on chromosomes 5 and 11. The QTL on chromosome 11 for foliage resistance to EB accounted for more than $50 \%$ of PVE. Owing to its main effect, these QTL probably have an influence on susceptibility to EB in plant foliage. QTL for defoliation independent from foliar resistance to EB were found on chromosomes 1,3 and 8. All four of these QTL were predicted to have a large effect on defoliation $(\mathrm{PVE}=30 \%-50 \%)$.

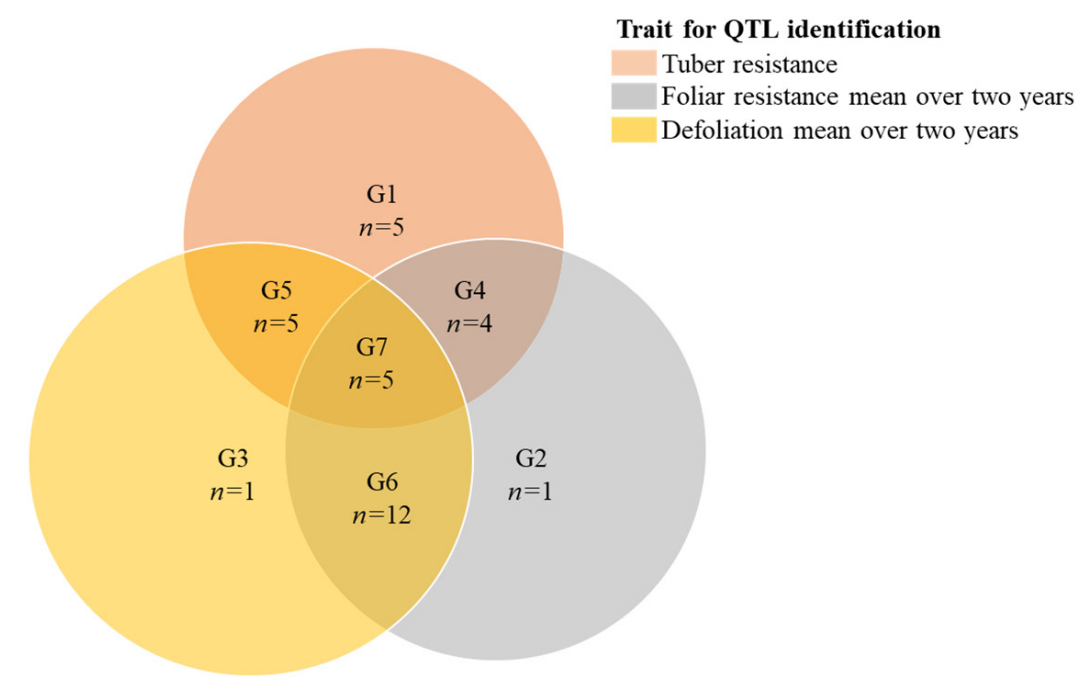

Figure 3. Venn's diagram showing the seven different groups of predicted quantitative trait loci (QTL) for tuber resistance to early blight, mean foliar resistance to early blight over 2014 and 2016 and mean defoliation over 2015 and 2016. Grouping are created according to the probable dependency of the QTL, where a QTL can only be explained by a single trait (groups 1 to 3) if the area of the predicted QTL does not overlap with the area of a QTL predicted by another trait, and is not present on the corresponding chromosome from the other parental linkage map. QTL in groups 4 to 6 are possibly overlapping (dependent) on two phenotypic traits. Group 7 contains QTL that could not be declared independent in any of the three phenotypic traits. 
Table 2. Significant quantitative trait loci (QTL) for tuber and foliar resistance to $A$. solani and defoliation. Chr: Chromosome. Groups 1 to 7 indicate which phenotypic traits the predicted QTL can be linked to. In bold are the QTL for foliar resistance and defoliation that are most likely to be independent from each other, PVE: Phenotypic variation explained. Mapping parent indicates in which of the two parental linkage maps the QTL was found. The position in cM is the area of the linkage group where the genetic signal reached the logarithm of the odds ratio (LOD) threshold. Main Q effect is estimated as the closest single nucleotide polymorphisms (SNPs) effect on the offspring phenotype, only significant effects $(P<0.05)$ are included; “-" indicates that no significant effect was detected in the offspring, greater $(\uparrow)$ and lower $(\downarrow)$ trait values were defined as the mean phenotype of the offspring compared to parent with corresponding genotype. The QTL code corresponds to the Supplementary Figures S2 and S3, containing linkage groups from the two parental linkage maps. The QTL code name contains information on the phenotypic trait the loci influences and which linkage group the loci was detected in.

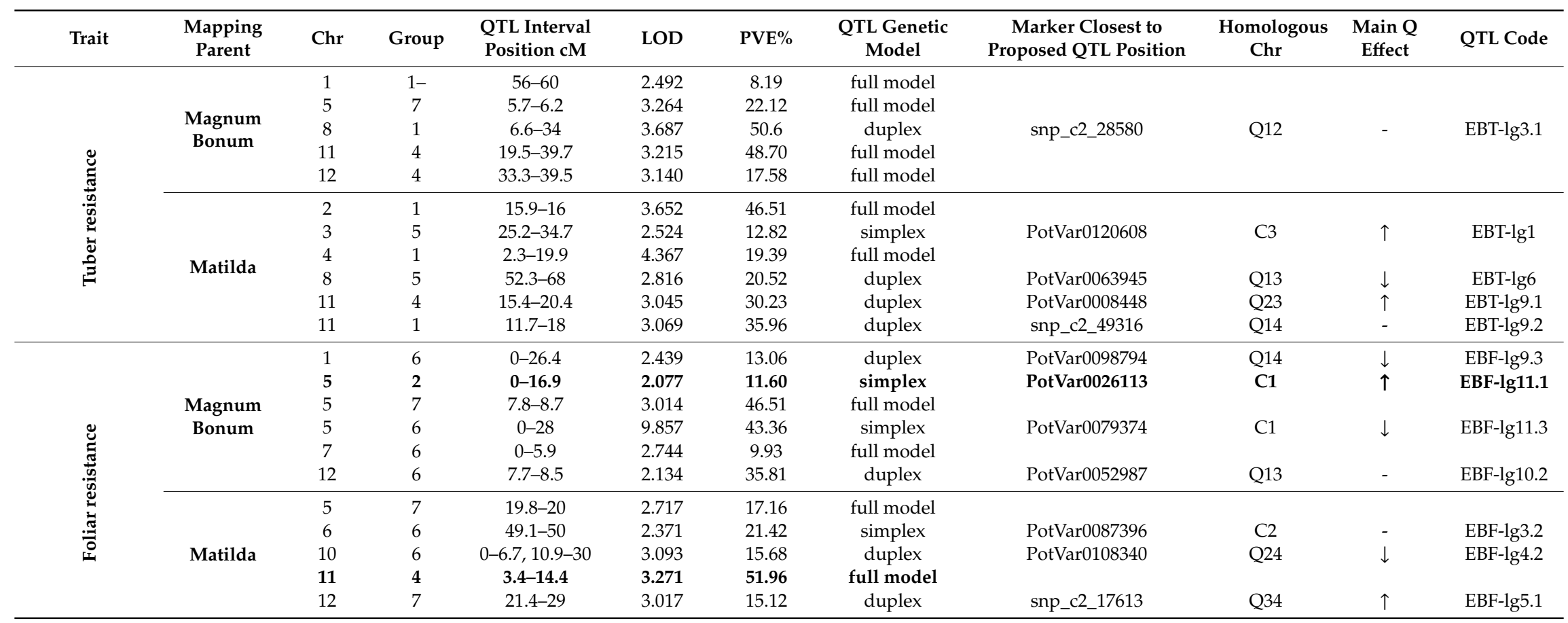


Table 2. Cont.

\begin{tabular}{|c|c|c|c|c|c|c|c|c|c|c|c|}
\hline \multirow{9}{*}{ 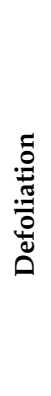 } & \multirow{8}{*}{$\begin{array}{c}\text { Magnum } \\
\text { Bonum }\end{array}$} & 1 & 3 & $12.3-16.1$ & 3.961 & 29.93 & full model & \multirow{3}{*}{ PotVar0044984 } & \multirow{3}{*}{ Q23 } & \multirow[b]{2}{*}{$\downarrow$} & \\
\hline & & 1 & 6 & $17.2-28.8$ & 2.700 & 29.88 & duplex & & & & \multirow[t]{2}{*}{ SEN-lg9.3 } \\
\hline & & 3 & 5 & $0-2.1$ & 3.327 & 42.61 & full model & & & & \\
\hline & & 3 & 5 & $29.8-30.1$ & 2.932 & 28.25 & duplex & \multirow[t]{2}{*}{ PotVar0094921 } & \multirow[t]{2}{*}{ Q34 } & \multirow[t]{2}{*}{ - } & \multirow[t]{2}{*}{ SEN-lg6.2 } \\
\hline & & 5 & 7 & $7.9-8.1$ & 4.094 & 51.29 & full model & & & & \\
\hline & & 7 & 6 & $0-22$ & 3.063 & 11.21 & full model & \multirow{3}{*}{ PotVar0079374 } & \multirow{3}{*}{$\mathrm{C} 1$} & \multirow{3}{*}{$\downarrow$} & \multirow{3}{*}{ SEN-lg11.3 } \\
\hline & & 8 & 5 & $21.5-30$ & 4.803 & 47.71 & full model & & & & \\
\hline & & 12 & 6 & $22.6-26.8$ & 4.765 & 52.92 & full model & & & & \\
\hline & Matilda & 6 & 6 & $49.8-50$ & 2.789 & 33.49 & full model & & & & \\
\hline
\end{tabular}


QTL analysis splitting the two years of phenotypic data for foliar resistance to EB and defoliation found 34 significant QTL (Supplementary Table S1). More significant QTL were found for foliar resistance in 2014 than in 2016 (12 and five significant QTL, respectively), while more QTL were detected in 2016 than in 2015 for defoliation (12 and five significant QTL, respectively). More QTL for EB resistance in foliage were found to be independent from defoliation when using the two years separately. All QTL for EB resistance in foliage, which were independent from defoliation, were noticed in 2014. QTL for foliar resistance to EB were found on several more chromosomes for the two years individually. The major effect QTL on chromosome 11, found when using the mean over two years, was detected only in 2014. This seems to be the same QTL as it was on the same linkage group using the same mapping parent; however, the confidence interval is slightly shifted. The minor effect QTL on chromosome 5 , which was significant when using the mean over two years, was not detected when using the data from the two years separately. Instead, QTL on chromosomes 1, 2, 4 and 10 were detected and independent from defoliation. The QTL for foliage resistance to EB on chromosome 10 detected in 2014 was also detected when using the mean over both years. However, the defoliation QTL, found when using both sets together, was not detected when considering the years separately, thus this QTL is now defined as independent.

The top five clones with low disease scores for both foliar and tuber EB were selected together with the two parents (Supplementary Table S2). Genotypes for major QTL (PVE > 20) for with a significant effect (Student's t-test, $P<0.01$ ) detected with a simplex or duplex model where checked. Out of all detected QTL, two for tuber resistance and one for foliar resistance to EB met these requirements. The QTL for tuber resistance on chromosome 8 showed a negative effect on the disease score; four out of five clones had the same genotype as the more resistant parent ("Matilda"). The QTL for tuber resistance on chromosome 11 had a positive effect on the disease score; all the top five clones had the same genotype as the more susceptible parent ("Magnum Bonum"). QTL for foliar resistance on chromosome 5 showed a negative effect on the disease score. All five clones had the same genotype as the more susceptible parent ("Matilda").

\section{Discussion}

One of the most effective methods against EB would be the cultivation of cultivars with a higher level of resistance [10]. To breed new resistant cultivars, there is a need to find suitable sources of resistance and to identify genetic markers that facilitate the selection in breeding populations. It has been shown that EB resistance is associated with late maturity $[10,20,48]$; therefore, introgression of the resistant genes for EB to the new commercial cultivars without the compromise in earliness is complicated. The linkage drag is the main barrier, particularly when transferring multiple genes and therefore, it could be one of the reasons which limited the progress of developing new commercial potato cultivars with improved EB resistance.

This study recorded a wide range of reactions to EB among the clones suggesting the presence of high-level resistance both in foliar and in tuber. The present study also recorded a significant correlation $(\mathrm{r}=0.32, P=0.001)$ between EB disease severities from 2014 and 2016. A lower level correlation between the defoliation in 2014 compared to 2015 and 2016 was observed. This was probably due to later emergence in 2014 when we used small greenhouse-produced seed tubers. This later emergence resulted in a low level of defoliation and less difference among the clones compared to the other two years.

To our knowledge, this study is the first attempt to map QTL using linkage analysis for resistance to EB in tetraploid potato. Linkage mapping in an outcrossing, tetraploid species is not as straightforward as for self-pollinating species, as they cannot yield a traditional $\mathrm{F}_{2}$ population and hence one has to map each of the parents separately [49]. Recently, new software that can conduct linkage maps for both parents at the time has been developed [50,51], and the implementation of this software might favor the identification of more closely-linked SNPs to the QTL found in this study. We were able to find two QTL for foliar resistance to EB on chromosomes 5 and 11 (LOD-2.077 and 3.271, PVE\%-11.60 and 
51.96, respectively), whereby both were independent of defoliation. The SNPs that map closely to these QTL should be taken into consideration when developing new markers for selection in potato breeding. The multitude of markers found for tuber resistance to EB additionally points to the quantitative nature of this trait, but these SNPs would also be considered for developments in marker-aided selection. The resolution of the linkage maps in this study is still quite low, which is apparent when studying the physical size of the confidence interval regions of the mapped QTL. This is to be expected considering the relatively small crossing population and the degree of linkage disequilibrium decay in potato [52]. Still, markers in proximity to the QTL can be linked to a significant impact on the offspring' phenotype. Finding cheap PCR primers for these QTL would be the first step towards applying marker-assisted selection for resistance breeding to EB in potatoes. However, denser mapping of the regions of the proposed QTL will be required for QTL where no significant phenotype-response was noticed. For example, the major QTL for foliar resistance to EB on chromosomes 6 and 12 may show a significant phenotypic response when looking at a closer-linked marker. Denser linkage maps, which can be achieved by increasing the size of the crossing population, could also result in an increased number of mapped QTL.

Up to date most of the research focused on foliar resistance. However, tuber rot is a potential threat and in parts of the world is already a problem [6]; therefore, it is also important to gain knowledge about tuber resistance to EB in cultivars and breeding lines. Our results revealed that there were significant differences in lesion size and lesion depth development $(P<0.001)$ among clones after inoculation of cut tubers with $A$. solani. We found a significant correlation between these two measurements $(r=0.66, P<0.001$, Figure 2B), indicating that both measurements could be appropriate for evaluation of resistance in tubers. However, the volume of the infected area could be a better measurement of the severity of infection because both the lesion diameter and depth of the infected area on the tuber will be taken into consideration. We have also noticed five QTL for tuber resistance, which were independent from the foliar resistance and defoliation, on chromosomes 1, 2, 4, 8 and 11 (Figure 3, Table 2). Among them, three QTL on chromosomes 2, 8 and 11 were predicted to have a large effect on tuber resistance. These QTL can be used for developing markers for breeding of EB tuber resistance in potato.

In the bi-parental population we also found that the degree of resistance in leaves did not correlate with resistance in tubers (Figure 2C), which agrees with our previous study [19]. A similar result was also found in another pathogen (Phytophthora infestans) [53], thus indicating that foliage and tuber resistance are determined by different genes. QTL for these two types of resistance are found at altogether different places in the genome, and this knowledge will further aid in preparing new crosses for developing new resistant cultivars. Some of the progeny clones had good resistance in both leaves and tubers (Supplementary Figure S2) and they could be potential candidates for EB resistance breeding programs. In addition, three overlapping QTL were identified on chromosome 11, which were only associated with foliar and tuber resistance (Figure 3, Table 2). The use of these QTL in MAS will improve breeding to EB (both for foliar and tuber resistance in potato).

In future work, the identified QTL for EB resistance in the present work need to be validated in other populations and different environments. In addition, integrating these QTL and transcriptomics can also assist in identifying putative genes responsible for EB resistance. All these important steps can facilitate the development of markers suitable for marker-assisted selection.

\section{Conclusions}

The present study has reported the response of potato germplasm to EB both in leaves and tubers. Some of the clones performed well in respect to both foliar and tuber resistance; therefore, they could be valuable candidates for breeding programs in the future. The identified QTL for EB resistance in the present work can be used for developing markers for aided-breeding of EB resistance in potato.

Supplementary Materials: The following are available online at http://www.mdpi.com/2073-4395/10/5/728/s1, Figure S1: Phenotype distributions of rAUDPC in 2014 and 2016 and rAUC of defoliation in 2014, 2015 and 2016. Figure S2: Early blight resistance among the progenies of a bi-parental population in a field experiment and in a 
tuber test; Figures S3 and S4: The genetic linkage map of QTL for foliar and tuber resistance to EB and defoliation in potato. Table S1: List of significant QTL for foliar resistance to early blight (EB) and defoliation for the years collected separately; Table S2: The genotypes of five offspring clones with highest resistance to EB in both foliage (mean over 2014 and 2016) and tuber and their two crossing parents.

Author Contributions: E.L. planned and designed the project. F.O. developed the bi-parental population and performed the experiments in the greenhouse and laboratory. E.L. and F.O. conducted the field experiments. F.O., E.L., C.S. and A.C. analyzed the data. F.O., C.S., R.O., A.C. and E.L. interpreted the results and contributed to the writing. All authors have read and agreed to the published version of the manuscript.

Funding: This research was supported by funding from the Swedish International Development Agency (Sida), Einar och Inga Nilssons Stiftelse för kirurgforskning och forskning inom jordbruket, and Stiftelsen för miljöstrategisk forskning (Mistra) and SLU through the Mistra Biotech project.

Acknowledgments: The authors acknowledge Ulrika Carlson-Nilsson for her assistance by providing tuber material for this research. We thank HZPC, Joure, The Netherlands for performing the SNP analysis.

Conflicts of Interest: The authors declare no conflicts of interest.

\section{References}

1. FAOSTAT. Food and Agriculture Organization. 2017. Available online: http://faostat.Fao.Org (accessed on 22 March 2018).

2. Shuman, J.; Christ, B. Integrating a host-resistance factor into the fast system to forecast early blight of potato. Am. J. Potato Res. 2005, 82, 9-19. [CrossRef]

3. van der Waals, J.E.; Korsten, L.; Aveling, T.A.S.; Denner, F.D.N. Influence of environmental factors on field concentrations of Alternaria solani conidia above a south african potato crop. Phytoparasitica 2003, 31, 353-364. [CrossRef]

4. Leiminger, J.H.; Hausladen, H. Early blight control in potato using disease-orientated threshold values. Plant Dis. 2012, 96, 124-130. [CrossRef] [PubMed]

5. Nnodu, E.C.; Harrison, M.D.; Parke, R.V. The effect of temperature and relative humidity on wound-healing and infection of potato tubers by Alternaria solani. Am. Potato J. 1982, 59, 297-311. [CrossRef]

6. Al-Mughrabi, K.I. Efficacy of oxidate for control of early blight (Alternaria solani) in potato storages. Plant Pathol. J. 2005, 4, 1-4.

7. Runno-Paurson, E.; Loit, K.; Hansen, M.; Tein, B.; Williams, I.H.; Maend, M. Early blight destroys potato foliage in the northern baltic region. Acta Agric. Scand. Sect. B-Soil Plant Sci. 2015, 65, 422-432. [CrossRef]

8. Kapsa, J.S.; Osowski, J. Host-pathogen interaction between Alternaria species and S. tuberosum under different conditions. Spec. Rep. 2012, 15, 107-112.

9. Edin, E.; Andersson, B. The early blight situation in Sweden-species abundance and strobilurin sensitivity. PPO Spec. Rep. 2014, 16, 83-84.

10. Rodriguez, M.A.D.; Brommonschenkel, S.H.; Matsuoka, K.; Mizubuti, E.S.G. Components of resistance to early blight in four potato cultivars: Effect of leaf position. J. Phytopathol. 2006, 154, 230-235. [CrossRef]

11. Campo Arana, R.O.; Zambolim, L.; Costa, L.C. Potato early blight epidemics and comparison of methods to determine its initial symptoms in a potato field. Rev. Fac. Nac. de Agron Medellín 2007, 60, 3877-3890.

12. Leiminger, J.H.; Adolf, B.; Hausladen, H. Occurrence of the F129L mutation in Alternaria solani populations in germany in response to qoi application, and its effect on sensitivity. Plant Pathol. 2014, 63, 640-650. [CrossRef]

13. Edin, E.; Liljeroth, E.; Andersson, B. Long term field sampling in Sweden reveals a shift in occurrence of cytochrome $b$ genotype and amino acid substitution F129L in Alternaria solani, together with a high incidence of the G143A substitution in Alternaria alternata. Eur. J. Plant Pathol. 2019, 155, 1-15. [CrossRef]

14. Odilbekov, F.; Edin, E.; Mostafanezhad, H.; Coolman, H.; Grenville-Briggs, L.J.; Liljeroth, E. Within-season changes in Alternaria solani populations in potato in response to fungicide application strategies. Eur. J. Plant Pathol. 2019, 155, 953-965. [CrossRef]

15. Haverkort, A.J.; Boonekamp, P.M.; Hutten, R.; Jacobsen, E.; Lotz, L.A.P.; Kessel, G.J.T.; Visser, R.G.F.; van der Vossen, E.A.G. Societal costs of late blight in potato and prospects of durable resistance through cisgenic modification. Potato Res. 2008, 51, 47-57. [CrossRef]

16. Herriott, A.B.; Haynes, F.L., Jr.; Shoemaker, P.B. Inheritance of resistance to early blight disease in tetraploid $\mathrm{x}$ diploid crosses of potatoes. HortScience 1990, 25, 224-226. [CrossRef] 
17. Abuley, I.K.; Nielsen, B.J.; Labouriau, R. Resistance status of cultivated potatoes to early blight (Alternaria solani) in Denmark. Plant Pathol. 2018, 67,315-326. [CrossRef]

18. Christ, B.J. Effect of disease assessment method on ranking potato cultivars for resistance to early blight. Plant Dis. 1991, 75, 353-356. [CrossRef]

19. Odilbekov, F.; Carlson-Nilsson, U.; Liljeroth, E. Phenotyping early blight resistance in potato cultivars and breeding clones. Euphytica 2014, 197, 87-97. [CrossRef]

20. Duarte, H.S.S.; Zambolim, L.; Rodrigues, F.A.; Paul, P.A.; Pádua, J.G.; Ribeiro Júnior, J.I.; Júnior, A.F.N.; Rosado, A.W.C. Field resistance of potato cultivars to foliar early blight and its relationship with foliage maturity and tuber skin types. Trop. Plant Pathol. 2014, 39, 294-306. [CrossRef]

21. Xue, W.; Haynes, K.G.; Qu, X. Characterization of early blight resistance in potato cultivars. Plant Dis. 2019, 103, 629-637. [CrossRef]

22. Boiteux, L.S.; Reifschneider, F.J.B.; Fonseca, M.E.N.; Buso, J.A. Search for sources of early blight (Alternaria solani) field resistance not associated with vegetative late maturity in tetraploid potato germplasm. Euphytica 1995, 83, 63-70. [CrossRef]

23. Zhang, R. Genetic characterization and mapping of partial resistance to early blight in diploid potato. Ph.D. Thesis, The Pennsylvania State University, University Park, PA, USA, 2004.

24. Ortiz, R.; Martin, C.; Iwanaga, M.; Torres, H. Inheritance of early blight resistance in diploid potatoes. Euphytica 1993, 71, 15-19. [CrossRef]

25. Christ, B.J.; Haynes, K.C. Inheritance of resistance to early blight disease in a diploid potato population. Plant Breed. 2001, 120, 169-172. [CrossRef]

26. Christ, B.J.; Haynes, K.G.; Vinyard, B.T. Inheritance of early blight resistance from open-pollinated 4x-2x potato hybrids. Am. J. Potato Res. 2002, 79, 403-410. [CrossRef]

27. Massa, A.N.; Manrique-Carpintero, N.C.; Coombs, J.; Haynes, K.G.; Bethke, P.C.; Brandt, T.L.; Gupta, S.K.; Yencho, G.C.; Novy, R.G.; Douches, D.S. Linkage analysis and QTL mapping in a tetraploid russet mapping population of potato. BMC Genet. 2018, 19, 87. [CrossRef]

28. Hamilton, J.P.; Hansey, C.N.; Whitty, B.R.; Stoffel, K.; Massa, A.N.; Van Deynze, A.; De Jong, W.S.; Douches, D.S.; Buell, C.R. Single nucleotide polymorphism discovery in elite north american potato germplasm. BMC Genom. 2011, 12, 302. [CrossRef]

29. Vos, P.G.; Uitdewilligen, J.G.; Voorrips, R.E.; Visser, R.G.; van Eck, H.J. Development and analysis of a 20k snp array for potato (Solanum tuberosum): An insight into the breeding history. Theor. Appl. Genet. 2015, 128, 2387-2401. [CrossRef]

30. Sharma, S.K.; Bolser, D.; de Boer, J.; Sønderkær, M.; Amoros, W.; Carboni, M.F.; D'Ambrosio, J.M.; de la Cruz, G.; Di Genova, A.; Douches, D.S. Construction of reference chromosome-scale pseudomolecules for potato: Integrating the potato genome with genetic and physical maps. G3 Genes Genomes Genet. 2013, 3, 2031-2047. [CrossRef]

31. Massa, A.N.; Manrique-Carpintero, N.C.; Coombs, J.J.; Zarka, D.G.; Boone, A.E.; Kirk, W.W.; Hackett, C.A.; Bryan, G.J.; Douches, D.S. Genetic linkage mapping of economically important traits in cultivated tetraploid potato (Solanum tuberosum L.). G3 Genes Genomes Genet. 2015, 5, 2357-2364.

32. Lindqvist-Kreuze, H.; Gastelo, M.; Perez, W.; Forbes, G.A.; de Koeyer, D.; Bonierbale, M. Phenotypic stability and genome-wide association study of late blight resistance in potato genotypes adapted to the tropical highlands. Phytopathology 2014, 104, 624-633. [CrossRef]

33. Santa, J.D.; Berdugo-Cely, J.; Cely-Pardo, L.; Soto-Suárez, M.; Mosquera, T. QTL analysis reveals quantitative resistant loci for Phytophthora infestans and Tecia solanivora in tetraploid potato (Solanum tuberosum L.). PLoS ONE 2018, 13, e0199716. [CrossRef] [PubMed]

34. Da Silva, W.L.; Ingram, J.; Hackett, C.A.; Coombs, J.J.; Douches, D.; Bryan, G.J.; De Jong, W.; Gray, S. Mapping loci that control tuber and foliar symptoms caused by PVY in autotetraploid potato (Solanum tuberosum L.). G3 Genes Genomes Genet. 2017, 7, 3587-3595.

35. Schönhals, E.M.; Ding, J.; Ritter, E.; Paulo, M.J.; Cara, N.; Tacke, E.; Hofferbert, H.-R.; Lübeck, J.; Strahwald, J.; Gebhardt, C. Physical mapping of QTL for tuber yield, starch content and starch yield in tetraploid potato (Solanum tuberosum L.) by means of genome wide genotyping by sequencing and the $8.3 \mathrm{~K}$ solcap snp array. BMC Genom. 2017, 18, 642. [CrossRef] [PubMed] 
36. Manrique-Carpintero, N.C.; Coombs, J.J.; Pham, G.M.; Laimbeer, F.P.E.; Braz, G.T.; Jiang, J.; Veilleux, R.E.; Buell, C.R.; Douches, D.S. Genome reduction in tetraploid potato reveals genetic load, haplotype variation, and loci associated with agronomic traits. Front. Plant Sci. 2018, 9. [CrossRef] [PubMed]

37. Tiemens-Hulscher, M.; Delleman, J. Potato Breeding: A Practical Manual for the Potato Chain; S.l.: Aardappelwereld, The Natherlands, 2013.

38. OEPP/EPPO. Eppo standards. Efficacy evaluation of plant protection products. In Fungicides and Bactericides; European and Mediterranean Plant Protection Organization: Paris, France, 2004; Volume 2.

39. Simmons, E.G. Alternaria: An identification Manual; CBS Fungal Biodiversity Centre: Utrecht, The Netherlands, 2007.

40. Gannibal, P.B.; Orina, A.S.; Mironenko, N.V.; Levitin, M.M. Differentiation of the closely related species, Alternaria solani and A. tomatophila, by molecular and morphological features and aggressiveness. Eur. J. Plant Pathol. 2014, 139, 609-623. [CrossRef]

41. Covarrubias-Pazaran, G. Genome-assisted prediction of quantitative traits using the R package sommer. PLOS ONE 2016, 11, e0156744. [CrossRef]

42. Hackett, C.A.; Milne, I.; Bradshaw, J.E.; Luo, Z. Tetraploidmap for windows: Linkage map construction and QTL mapping in autotetraploid species. J. Hered. 2007, 98, 727-729. [CrossRef]

43. Rak, K.; Bethke, P.C.; Palta, J.P. QTL mapping of potato chip color and tuber traits within an autotetraploid family. Mol. Breed. 2017, 37, 15. [CrossRef]

44. Bradshaw, J.E.; Hackett, C.A.; Pande, B.; Waugh, R.; Bryan, G.J. QTL mapping of yield, agronomic and quality traits in tetraploid potato (Solanum tuberosum subsp tuberosum). Theor. Appl. Genet. 2008, 116, 193-211. [CrossRef]

45. McCord, P.H.; Sosinski, B.R.; Haynes, K.; Clough, M.; Yencho, G. QTL mapping of internal heat necrosis in tetraploid potato. Theor. Appl. Genet. 2011, 122, 129-142. [CrossRef]

46. Luo, Z.; Hackett, C.; Bradshaw, J.; McNicol, J.; Milbourne, D. Construction of a genetic linkage map in tetraploid species using molecular markers. Genetics 2001, 157, 1369-1385. [PubMed]

47. Hackett, C.; Bradshaw, J.; McNicol, J. Interval mapping of quantitative trait loci in autotetraploid species. Genetics 2001, 159, 1819-1832. [PubMed]

48. Pelletier, J.R.; Fry, W.E. Characterization of resistance to early blight in three potato cultivars: Incubation period, lesion expansion rate, and spore production. Phytopathology 1989, 79, 511-517.

49. Meyer, R.; Milbourne, D.; Hackett, C.; Bradshaw, J.; McNichol, J.; Waugh, R. Linkage analysis in tetraploid potato and association of markers with quantitative resistance to late blight (Phytophthora infestans). Mol. Gen. Genet. 1998, 259, 150-160. [CrossRef] [PubMed]

50. Hackett, C.A.; Boskamp, B.; Vogogias, A.; Preedy, K.F.; Milne, I. Tetraploidsnpmap: Software for linkage analysis and QTL mapping in autotetraploid populations using SNP dosage data. J. Hered. 2017, 108, 438-442. [CrossRef]

51. Bourke, P.M.; van Geest, G.; Voorrips, R.E.; Jansen, J.; Kranenburg, T.; Shahin, A.; Visser, R.G.; Arens, P.; Smulders, M.J.; Maliepaard, C. Polymapr-linkage analysis and genetic map construction from F1 populations of outcrossing polyploids. Bioinformatics 2018, 34, 3496-3502. [CrossRef]

52. Vos, P.G.; Paulo, M.J.; Voorrips, R.E.; Visser, R.G.F.; van Eck, H.J.; van Eeuwijk, F.A. Evaluation of LD decay and various LD-decay estimators in simulated and SNP-array data of tetraploid potato. Theor. Appl. Genet. 2017, 130, 123-135. [CrossRef]

53. Kirk, W.; Felcher, K.; Douches, D.; Niemira, B.; Hammerschmidt, R. Susceptibility of potato (Solanum tuberosum L.) foliage and tubers to the US8 genotype of Phytophthora infestans. Am. J. Potato Res. 2001, 78, 319-322. [CrossRef]

(C) 2020 by the authors. Licensee MDPI, Basel, Switzerland. This article is an open access article distributed under the terms and conditions of the Creative Commons Attribution (CC BY) license (http://creativecommons.org/licenses/by/4.0/). 